\title{
Particle processing on the labial palps of Mytilus edulis and Placopecten magellanicus (Mollusca: Bivalvia)
}

\author{
Peter G. Beninger ${ }^{1, *}$, Sylvie D. St-Jean ${ }^{2}$ \\ ${ }^{1}$ Département de Biologie, Faculté des Sciences, Université de Moncton, New Brunswick, Canada E1A 1L1 \\ ${ }^{2}$ Environmental Studies and Aquaculture Division, Science Branch, Fisheries and Oceans, Moncton, New Brunswick, \\ Canada E1C 9B6
}

\begin{abstract}
In order to understand particle processing on the labial palps of suspension-feeding bivalves, mucocyte mapping and visual observations were performed on adult Mytilus edulis (Fam. Mytilidae) and Placopecten magellanicus (Fam. Pectinidae). Mucocyte contents were divided into categories depending on staining affinity for periodic acid-Schiff and alcian blue. The mucocyte distribution was determined by counts at representative sites on the palps, done on stained whole mounts or histological sections. Functional correlates for $M$. edulis were obtained using video endoscopy; this technique was compared to observations of carmine particle transport on specimens from which 1 valve had been removed. Video endoscopy was precluded in $P$. magellanicus due to the large and extremely sensitive arborescent lips; the behaviour of carmine particles deposited on the palps was therefore observed for this species. Mucus-particle cords are removed from the gill ventral particle groove by the cilia of the dorsal fold of the $M$. edulis palp at right angles to the current flow; highviscosity acid (AMPS) and acid-dominant (ADMPS)-containing mucocytes probably stabilize the cord at this point. The position of the retractable dorsal fold determines whether the cords are rejected or processed for ingestion. When the specimen's ingestıve capacity is overloaded, the arriving cords are transported parallel to and upon the palp crests to the palp ventral margin, and then to the posteriormost tip of the palp for rejection. This rejection pathway is characterized by transport perpendicular to or counter to current flow and high proportions of AMPS mucocytes. When the ingestive capacity of the specimen is not exceeded, mucus-particle cords are directed into the palp particle groove, where they are transformed into a slurry by the mechanical action of the palp crests and dorsal fold, and probably also the addition of low-viscosity neutral mucopolysaccharides present on the palp crests. The resulting slurry is amenable to both ingestion and particle selection; selected particles continue their anteriorward movement in the palp particle groove, while rejected particles are transported ventrally in the AMPS-rich crest troughs to join the rejection pathway along the palp ventral margin. The palp rejection site for $P$. magellanicus is also the AMPS-rich ventro-posterior margin, which terminates in a mixed mucopolysaccharide (MMPS)-rich reflected tip, probably related to the valve-clapping voidance of pseudofeces. Both the oral groove and the crest summits contain almost exclusively MMPS, suggesting that in this species the labial palps are mostly involved in ingestive particle handling, as opposed to $M$. edulis. Differences in gill structure and function may account for this putative difference in palp function. The combination of mucocyte mapping and video endoscopy (where possible) significantly enhances our understanding of bivalve feeding mechanisms.
\end{abstract}

KEY WORDS: Bivalves Feeding $\cdot$ Palps $\cdot$ Endoscopy $\cdot$ Mucocytes $\cdot$ Mytilus $\cdot$ Placopecten

\section{INTRODUCTION}

Recent progress in investigative techniques has greatly improved the knowledge of bivalve suspensionfeeding mechanisms (Beninger et al. 1991, 1993, Ward

\footnotetext{
•E-mail: beningp@bosoleil.ci.umoncton.ca
}

et al. 1991). Video endoscopy allows the determination of particle transport and water currents, and also allows the visual observation of mucus-particle masses and cords (Beninger et al. 1992, Tankersley \& Dimock 1992, 1993, Ward et al. 1993, 1994). Mucocyte mapping enables the determination of mucocyte location, distribution, and secretion type. These data can be used in 
conjunction with video endoscopy to elucidate the roles of mucus in particle transport. In a recent study, it was shown that a division of labour (particle transport for further processing vs rejection) was achieved on the heterorhabdic gill of the scallop Placopecten magellanicus, based on mucocyte type and distribution. On the homorhabdic mussel Mytilus edulis gill, no such division of labour was possible (Beninger et al. 1993).

To date, the gills have been the quasi-exclusive objects of such studies; a notable exception is the labial palps of Crassostrea virginica, for which video-endoscopic data are available (Ward et al. 1994). In addition to the gills, several other organs play important roles in particle handling: labial palps, lips and mantle (Kellogg 1915, Bernard 1974, Foster-Smith 1975, 1978, Kiørboe \& Møhlenberg 1981, Theisen 1982, Newell \& Jordan 1983, Shumway et al. 1985); a complete understanding of the mechanisms of particle processing in bivalves must therefore include investigations of these organs.

Recent studies of the labial palps of 2 pectinid species (Beninger et al. 1990) and of Mytilus edulis (Beninger et al. 1995) showed the labial palp morphology to be highly complex. Based on previous endoscopic studies of the gills of pectinids and mytilids (Beninger et al. 1992, Ward et al. 1993), it was apparent that in $M$. edulis the palps were an important site for ingestion volume control and the only organs capable of effecting particle selection. This conclusion was consistent with earlier studies using less refined techniques (Bernard 1974, Foster-Smith 1975, 1978, Kiørboe \& Møhlenberg 1981, Theisen 1982, Newell \& Jordan 1983), which also pointed to the labial palps as a site of ingestion volume control and particle selection in bivalves. In Placopecten magellanicus, however, the gills are also major sites of ingestion volume control (Beninger et al. 1992) and probably also selection (Atkins 1937), suggesting that not only the structure but also the function of the labial palps differs in these 2 species, depending on the respective functions of the gills. It is therefore most appropriate to further investigate the labial palps, in order to determine how ingestion volume control and selection are effected. The present study seeks to address these questions using the complementary techniques of video endoscopy and mucocyte mapping in $M$. edulis and $P$. magellanicus.

\section{MATERIAL AND METHODS}

Sampling. Three adult Mytilus edulis and 3 adult Placopecten magellanicus were used for histological preparations, while an additional $7 \mathrm{M}$. edulis and $5 P$. magellanicus were used for in vivo observations. The mussels were collected from the intertidal zone at Passamaquoddy Bay (New Brunswick, Canada) and from Mahone Bay (Nova Scotia, Canada) lease sites in May and November 1992. Bivalves destined for histological preparation were held in a recirculating aquarium containing artificial seawater $\left(31 \%, 5^{\circ} \mathrm{C}\right)$ for an acclimation period of $30 \mathrm{~d}$. They were fed weekly with $2.0 \mathrm{~g}$ of dried Tetraselmis sp. (Algal 161, Celsys, Cambridge, England), suspended in $1 \mathrm{l}$ of seawater. Bivalves used for in vivo observations were either held in a flowthrough seawater system at the Huntsman Marine Laboratory (observation of carmine particles) or in a recirculating natural seawater system $\left(15\right.$ to $16^{\circ} \mathrm{C}$, $33 \%$ ) at the University of New Brunswick - St. John (video endoscopy), where they were fed biweekly with a mixture of unicellular algae (Chaetoceros muelleri, Dunaliella and T-Isochrysis galbana) at approximately 10000 cells $\mathrm{ml}^{-1}$ final concentration.

Specimen preparation and anatomical terminology. The labial palps used for histology were carefully dissected out using microsurgical instruments and a dissecting microscope, immediately fixed in aqueous Bouin's medium for a minimum of $48 \mathrm{~h}$ and rinsed with running water for a minimum of $12 \mathrm{~h}$.

In addition to the anatomical terminology developed for the scallop and mussel palps in Beninger et al. (1990 and 1995 respectively), the following topological terms and definitions were used in this study

Section: serial slice obtained with a microtome; all counts were performed on tissue sections.

Region: division of an organ depending on anatomical orientation, e.g. posterior region of palp.

Area: representative subdivision of a region within which counts were performed, e.g. postero-ventral area of palp. Subdivision based on topographical features or marked differences in mucocyte distribution.

Zone: either a specific component of an anatomical feature, or a $100 \mu \mathrm{m}$ length of sectioned epithelium in a given area lacking such features, within which all mucocytes were counted, e.g. trough of palp ridge, lateral margin of palp. Zones are the counting units.

Staining and counting. The palps were dehydrated with a graded ethanol series, clarified in Hemo-De ${ }^{3}$ (Fisher Scientific), embedded in paraffin and sectioned at $10 \mu \mathrm{m}$. This thickness corresponds to the mean mucocyte length, therefore minimizing the probability of overlapping mucocytes and maximizing contrast. Three series of 40 sections, corresponding to the beginning, middle and end of an embedded block, were obtained from each region. The sections were mounted on 4 slides (10 sections per slide) and then stained using the combined periodic acid-Schiff (PAS) and alcian blue technique. The specificity of this protocol as well as the standardization of staining affinity were determined as in Beninger et al. (1993). 
Mucocyte counts were performed using a compound microscope at $100 \times$, as follows:

Three sections per slide (first, fourth and eighth) were counted for each of the 3 series of 40 sections. The mucocyte counts of each zone were performed twice: first in one direction and then in the opposite. A maximum of $5 \%$ error was ensured by performing an additional count whenever the $5 \%$ limit was exceeded. The means of all 3 individuals and corresponding standard deviations were calculated for each zone.

The labial palps of Mytilus edulis were divided into 4 ridged areas as shown in Fig. 1.2, as well as the dorsal fold area (Fig. 2.2); the palps of Placopecten magellanicus were divided into 9 ridged areas as represented in Fig. 5.2, as well as the oral groove (Fig. 6) and 2 ventral margin areas (Fig. 7) (due to the greater prominence of this region compared to $M$. edulis) Mucocytes were counted in the zones contained within these areas. At various locations on the mussels' palps, mucocytes were present in more or less discrete clusters situated under the basal lamina. As a precise count of the mucocyte clusters was impossible, the following semiquantitative scale was employed: 4: individual mucocytes indistinguishable; 3 : individual mucocytes partially distinguishable; 2 : some individual mucocytes distinguishable; 1 : all mucocytes distinguishable.

In vivo observations. The video-endoscopic technique of Ward et al. (1991) was used to study the movement of particles on the labial palps in Mytilus edulis. As mucus is not always visible using this technique, reflective paint particles ( 1 to $2 \mu \mathrm{m}$ ) were added to the algal mixture and presented to the inhalent siphon in a dropwise fashion. These observations were compared to the movement of carmine particles deposited directly on the palps of individuals which had 1 valve removed.

Attempts at video-endoscopic observation of particle treatment on the palps of Placopecten magellanicus were repeatedly frustrated by the extreme sensitivity of the arborescent lips which surround these organs. Hence, only observations using carmine particles (as above) were performed for this species.

\section{RESULTS}

\section{Color standardization and mucocyte types}

Table 1 presents the colour standardization results. Based on staining differences using the PAS-alcian blue technique, the following types of mucocyte secretions could be clearly distinguished: acid, neutral, mixed (equal proportions of neutral and acid secretion)
Table 1 Mucoclyte secretion type on palps of Mytilus edulis and Placopecten magellanicus

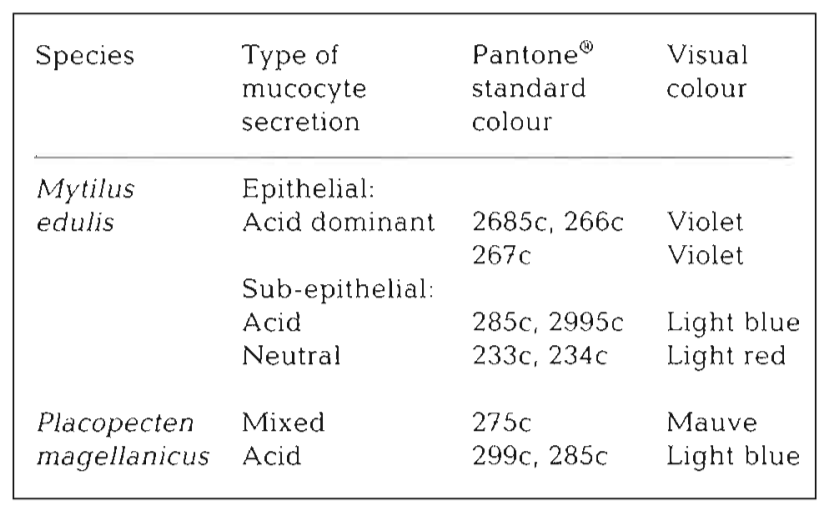

or acid-dominant (more acid than neutral secretion within the mucocyte) (Beninger et al. 1993).

\section{Data presentation}

The quantitative and semiquantitative mucocyte data are presented as means and standard deviations for each counting zone. Statistical testing for significant differences was not performed, for several reasons. First, no experimental hypotheses could be elaborated a priori, and therefore tested, since nothing was known about actual or envisaged mucocyte distribution on these surfaces. Second, the data include both continuous and discontinuous variables. Third, the correspondence between statistically significant and physiologically significant differences is not established for this system. Consequently, data presentation is restricted to major trends visible in the frequency histograms.

\section{Mytilus edulis}

Mucocyte distribution

Three mucocyte types were identified on the mussel labial palps: acid mucopolysaccharides (AMPS), those with acid-dominant mucopolysaccharide secretions (ADMPS) and those with neutral mucopolysaccharide secretions (NMPS). The mucocytes were situated either in the epithelium (Fig. 1.1.i) or beneath the basal lamina of the epithelium (Fig. 1.1.ii).

Palp crests. A low mucocyte density was found on the mussel palps; the maximum density never exceeded 3.6 per $100 \mu \mathrm{m}$, and no density gradient was observed. The mucocytes were situated at very specific locations on the palp. The epithelial acid mucopolysaccharides (AMPS) were situated on the posterior zone of the crest summits (Fig. 1.1.i.A, 1.2, 1.3) of the posterior area and on the mid- 


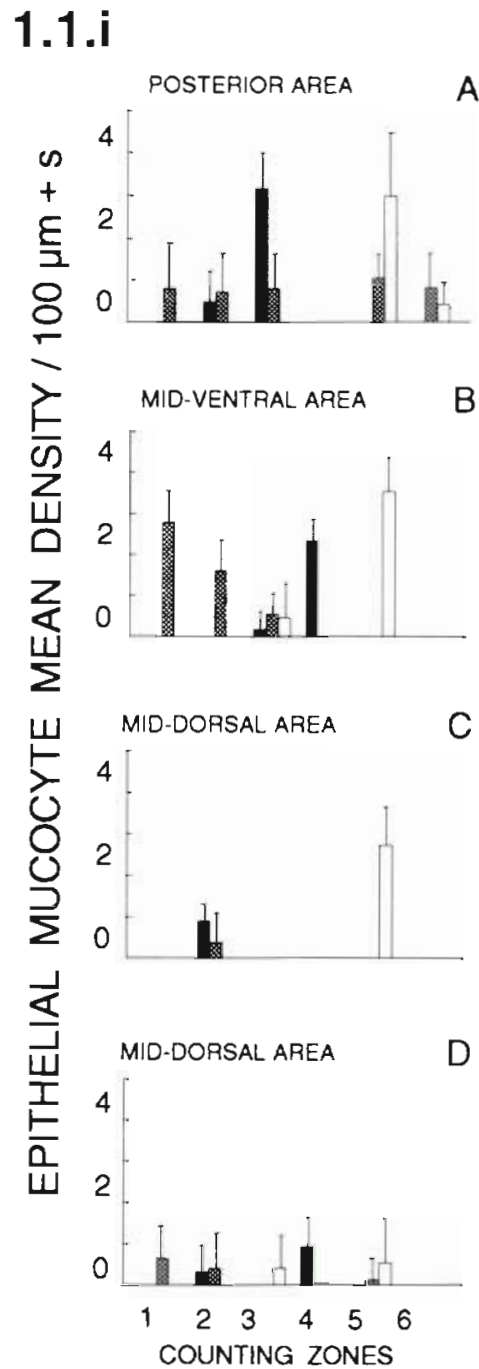

1.1.ii

A

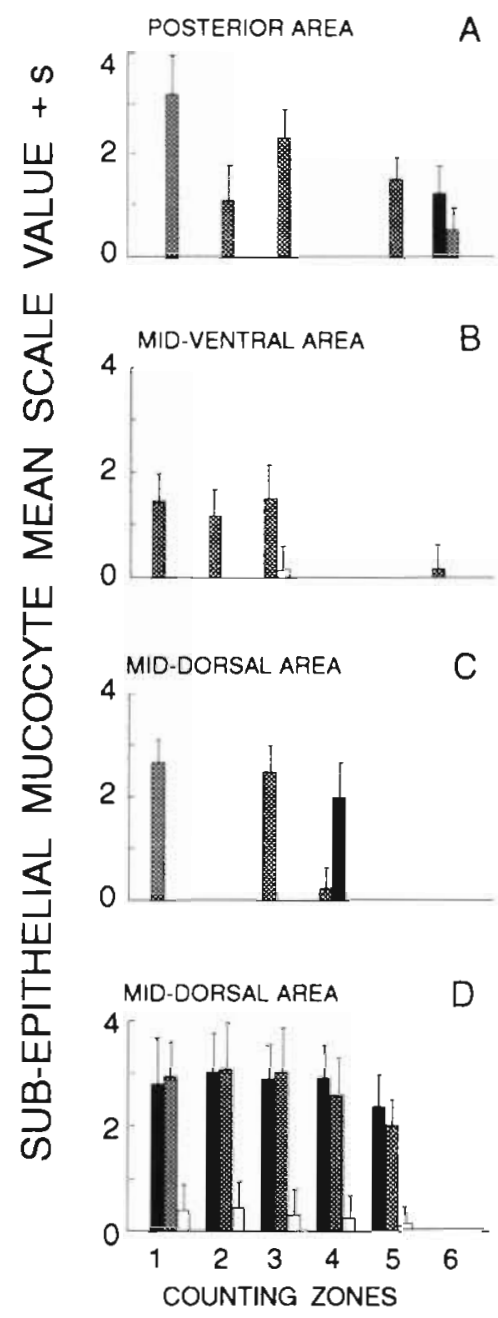

acid secretion

acid-dominant secretion

neutral secretion

\section{2}

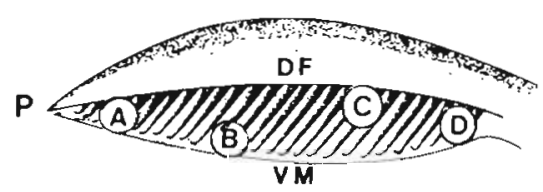

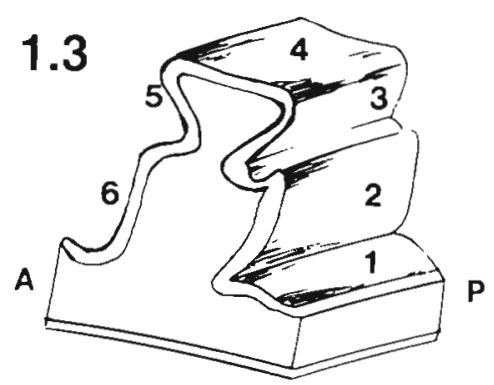

Fig. 1. Mytilus edulis. Mucocyte distribution (means + standard deviations) on labial palp ridged surface. (1.1) Mucocyte distribution at 4 counting areas (shown in Fig. 1.2) on ridged surface. (1.1.i) Distribution of epithelial mucocytes at 4 counting areas. (1.1.ii) Distribution of sub-epithelial mucocytes at 4 counting areas; semi-quantitative scale (see text). (1.2) Drawing of labial palp showing dorsal fold (DF), ventral margin (VM), posteriormost extremity (P), and 4 counting areas (A-D). (1.3) Diagram of a palp crest, showing trough counting zone (1) and crest counting zones (2-6); A: anterior; P: posterior dle zone of the crest summits of the midventral area (Fig 1.1.i.B, 1.2, 1.3), with $3.2 \pm 0.8$ and $2.4 \pm 0.5$ mucocytes per $100 \mu \mathrm{m}$ respectively. The epithelial neutral mucopolysaccharides (NMPS) were situated on the anterior zone of the crest summit of the posterior and middle areas, with a uniform density of approx. 3 per $100 \mu m_{i}$ the density was less than 1 mucocyte per $100 \mu \mathrm{m}$ for the anterior mid-dorsal area (Fig. 1.1.i.D). The epithelial ADMPS reached their maximal density in the troughs and the posterior crest folds of the mid-ventral area (Fig. 1.1.i.A-C) and were relatively scarce elsewhere.

Maximal densities of sub-epithelial AMPS and ADMPS were observed in the anterior area of the palp (Fig. 1.1.ii.D) with a semi-quantitative number of 3 . The other areas presented mostly sub-epithelial ADMPS on the posterior zones of the crests (Fig 1.1.ii.A-C), with relatively few on the anterior zones.

Palp dorsal fold. The palp dorsal fold was subdivided into 3 counting zones: the free margin was termed the prefusion zone, the point of fusion with the palp was called the fusion zone, and the remainder was called the post-fusion zone (Fig. 2.3). Lengths $(100 \mu \mathrm{m})$ of sectioned epithelium were counted for each zone. Epithelial mucocytes were absent from the prefusion zone, but epithelial AMPS presented an increasing density from the point of fusion dorsally; this was accompanied by a reciprocal distribution of epithelial ADMPS and NMPS (Fig. 2.1). The sub-epithelial ADMPS presented a decreasing gradient from the pre- to the post-fusion zone, while the sub-epithelial AMPS and NMPS increased from the pre-fusion to the fusion zone. In the post-fusion zone, the AMPS levelled off, while the NMPS decreased (Fig, 2.1). Taken together, the epithelial and sub-epithelial AMPS + ADMPS were much more numerous than the corresponding NMPS on the palp dorsal fold.

Ventral margin. Due to the difficulty of obtaining a well-defined ventral margin, no rigorous counts of this sur- 
face were performed. However, qualitative visual observations indicated that the AMPS attained their maximum density on the posteriormost area, whereas the ADMPS presented their minimum density here.

\section{In vivo observations}

The Mytilus edulis specimens proved to be quite amenable to direct endoscopic observation. The individuals used for the study appeared well acclimatized to the presence of the endoscope: siphons and tentacles were deployed, indicating normal feeding behavior. The palps were very agile and dynamic, with different parts effecting various movements, as explained below.

The dorsal fold could position itself in the vicinity of the gill ventral particle groove, where it could pull mucus-particle cords from the gill particle groove; these cords were then directed to the palp particle groove. The mucus-particle cord assumed an S-shape as it left the gill particle groove and was transported to the palp particle groove, probably due to opposing beats on the ciliated epithelium (Fig. 3.1). Within the palp particle groove, the mucus-particle cord was transported anteriorly. The mucusparticle cord was subsequently subjected to either of 2 treatments, resulting in either rejection or pre-ingestive processing.

Rejection. The mucus-particle cord was directed ventrally on the palp in the case of rejection. Initially, the dorsal fold retracted, placing the palp particle groove at the same level as the gill particle groove, thereby preventing the mucus cord from entering the palp particle groove for fluidization. The mucus-particle cord was then transported above and parallel to the palp crests, toward the ventral margin of the palp, from whence it proceeded to the ventro-posterior tip of the palp, where it accumulated as pseudofeces (Fig. 4).

Pre-ingestive processing. Material directed anteriorly was destined for pre-ingestive processing. The mucus-particle cord was subjected to mechanical stress by both the dorsal fold, which presented alternate contraction-elongation movements, and by the crests of the palp ridges, which exhibited vigorous flexion movements (Fig. 3.2, 3.3). As a result, the mucus-particle cord disintegrated into smaller pieces;

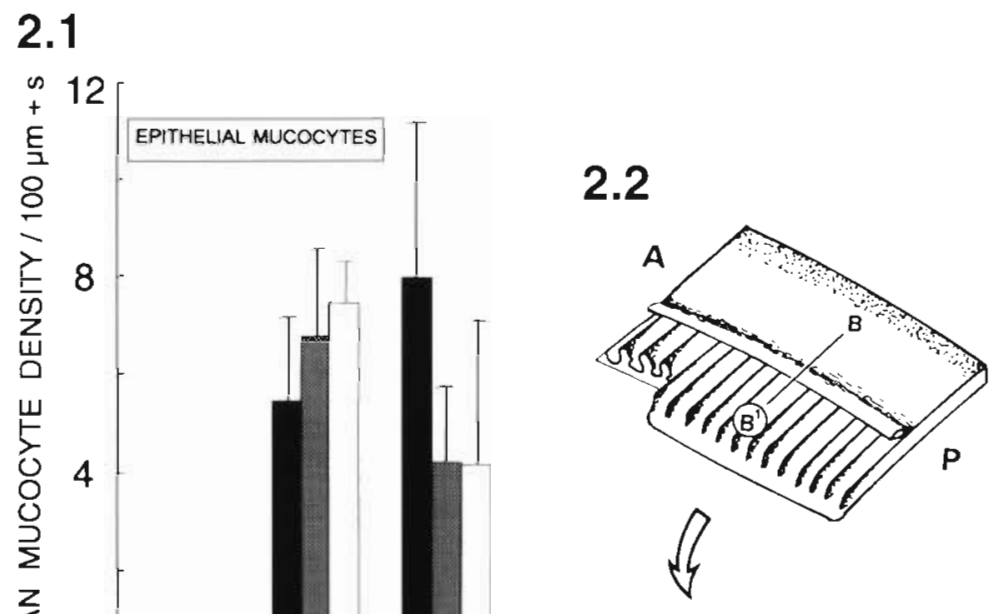

2.3
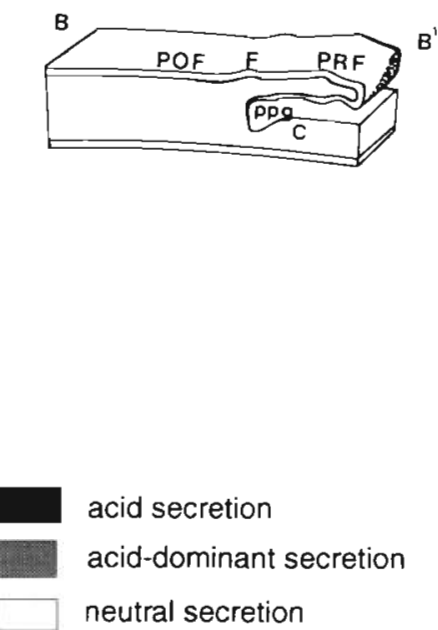

Fig. 2. Mytilus edulis. Mucocyte distribution (means + standard deviations on palp dorsal fold. (2.1) Distribution of epithelial and sub-epithelial mucocytes on 3 counting zones shown in Fig. 2.3. (2.2) Mid-region of labial palp, showing plane of section $\left(B-B^{1}\right)$ of dorsal fold for subsequent counts. A: anterior; P: posterior. (2.3) Diagram of dorsal fold, divided into 3 counting zones: pre-fusion (PRF, prior to fusion with the palp crests), fusion (F), and post-fusion (POF). ppg: palp particle groove

the material also appeared to become less viscous and more flocculent (Fig. 3.4-3.6). Some of this material continued anteriorly, presumably for ingestion; other particles disappeared into the crest troughs, re-emerging at the palp ventral margin where they were then transported as above for rejected material.

Comparison with observations of carmine particle transport. The anatomical relationship between the gill and labial palp is modified when the adductor muscles are cut and 1 valve removed, even under water. Although the sequence of normal particle arrival on the labial palps therefore could not be studied, transport of carmine particles deposited directly on the dorsal fold conformed to the 2 rejection pathways described above. 

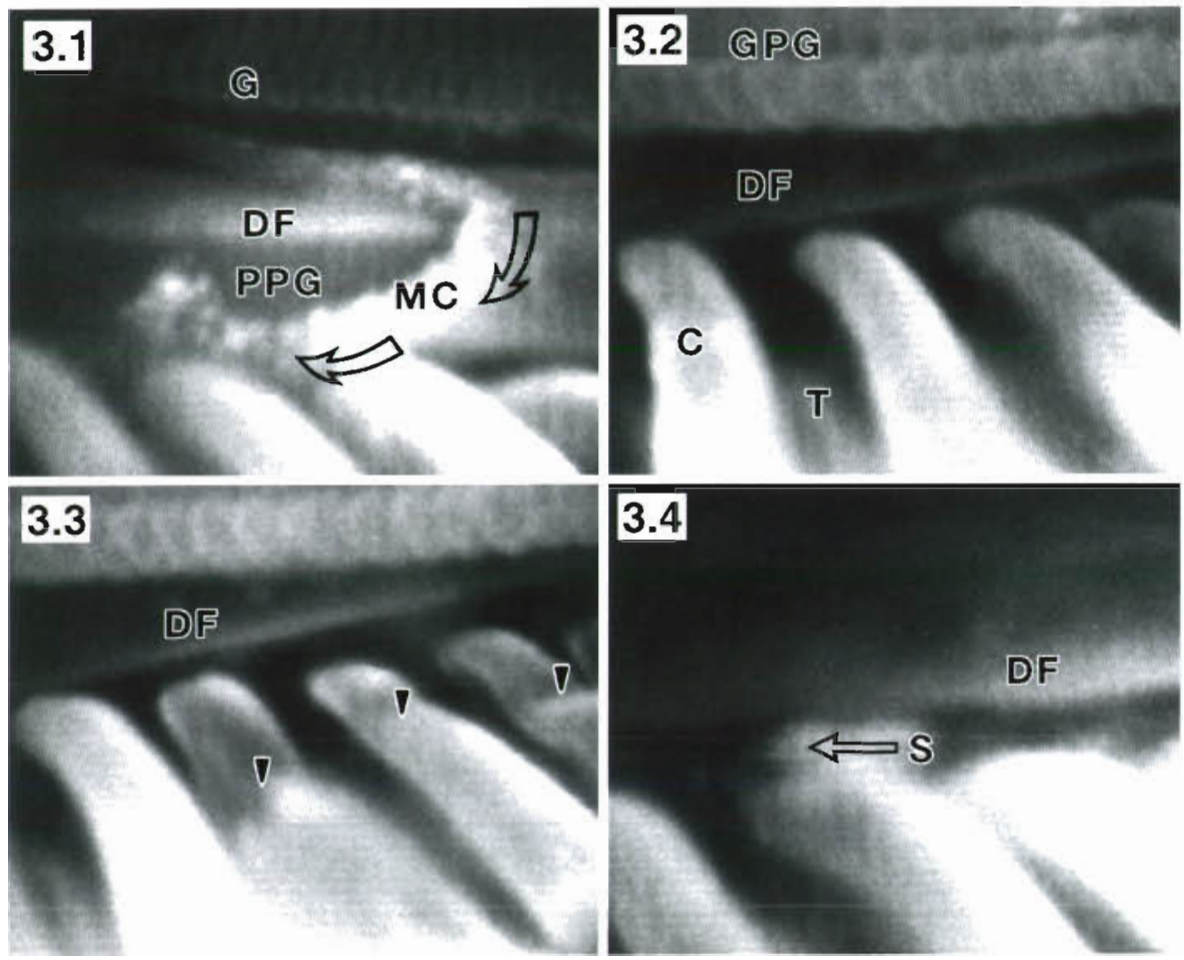

Fig. 3. Mytilus edulis. Videoendoscopic observations of particle processing on the labial palps. (3.1) Mucus-particle cord (MC) arriving from gill $(G)$ is pulled over the dorsal fold (DF) in an Sshape and begins to move anteriorly in the palp particle groove (PPG). (3.2) Region slightly anterior to 3.1, showing in vivo anatomical relationship between gill particle groove (GPG), dorsal fold of palp (DF), crests (C) and troughs (T). (3.3) Same as 3.2, but mucus cord about to arrive. Note localized contractions of the palp crests (arrows). (3.4) Arrival of mucus cord from 3.1. Note that it has been transformed into a flocculent slurry (S) by the mechanical action of the dorsal fold and palp crests, as well as addition of low-viscosity NMPS by the palp crests (see text). $(3.5,3.6)$ The slurry is pressed up against the dorsal fold by a palp crest and released as it passes anteriorly

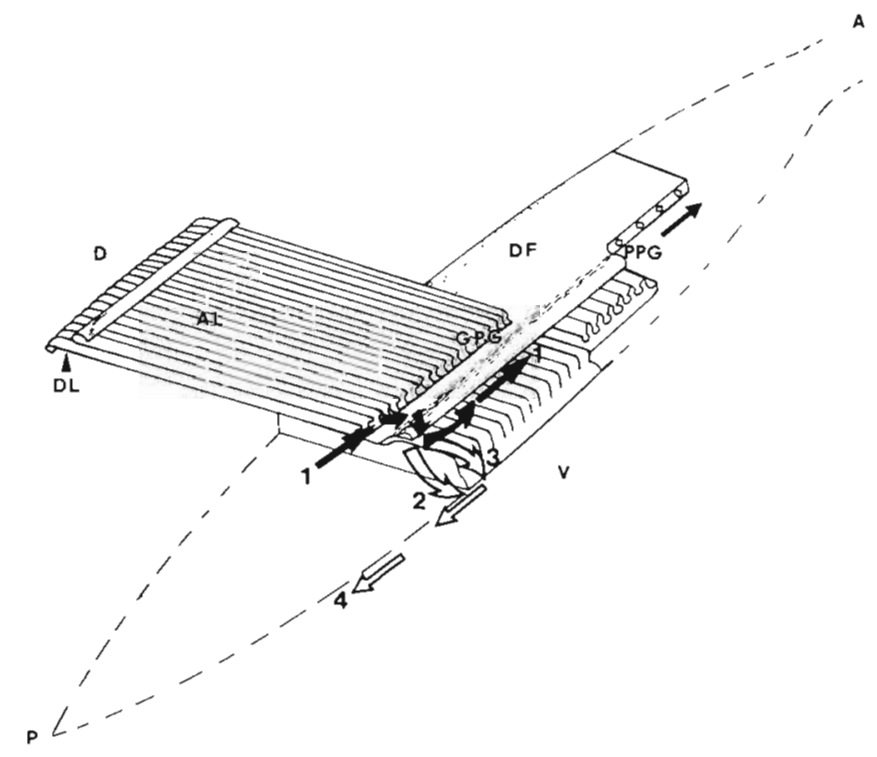

Fig. 4. Mytilus edulis. Summary of particle processing on the labial palp. Mucus-particle cord arriving in gill particle groove (GPG) is pulled out by cilia on dorsal fold (DF) and directed ventrally to the palp particle groove (PPG). Three trajectories are possible: if the ingestive/handling capacity is not overloaded, fluidization of the mucus-particle cord creates a flocculent slurry (see text), from which selected particles proceed anteriorly for ingestion (1); rejected particles are deviated into the palp troughs and transported to the ventral margin (2), where they begin to move posteriorly; if the ingestive/handling capacity is overloaded, the mucus-particle cord is shunted directly to the ventral margin without fluidization, where it begins to move posteriorly (3). The common rejection pathway is a posterior movement on the ventral margin (4). toward the posteriormost tip of the palp. Dominant pallial current postero-anterior. A: anterior; AL: ascending lamella of gill; D: dorsal; DL: descending lamella of gill; P: posterior; V: ventral 


\section{Placopecten magellanicus}

\section{Mucocyte distribution}

Two types of mucocyte were found on the scallop palp: acid-secretion mucopolysaccharide (AMPS) and mixed-secretion mucopolysaccharide (MMPS). Mucocyte distribution was very different for the general ridged surface and the ventral margin of the palp.

Ridged surface. The mucocyte distribution on the ridged surface was related to positions on the palp crests and troughs. The greatest mucocyte density was consistently found on the palp ridge crest summits (Fig. 5.1, 5.3), in all areas of the palp ridged surface (Fig 5.1, 5.2), where MMPS clearly dominated compared to AMPS (Fig. 5.1). The crest sides and troughs contained very few mucocytes. The oral groove (Fig. 6.2) presented a uniform mucocyte distribution throughout, with a marked dominance of MMPS (14.9 \pm 1.5 per $100 \mu \mathrm{m}$ ) and few AMPS (Fig. 6.1).
Over the palp ridged surface, 2 increasing density gradients were observed for the palp crest MMPS: (1) from anterior to posterior, ranging from $19.2 \pm 3.8$ to $23.8 \pm 7$ per $100 \mu \mathrm{m}$ for the dorsal region (Fig. 5.1.G-I), from $19.4 \pm 4.2$ to $25.5 \pm 7.8$ per $100 \mu \mathrm{m}$ for the middle region (Fig. 5.1.D-F), and from $20 \pm 4$ to $30 \pm 9.7$ per $100 \mu \mathrm{m}$ for the ventral region (Fig. 5.1.A-C), and (2) from the dorsal posterior region to the ventral posterior region: ranging from $23.8 \pm 7$ (Fig. 5.1.I) to $30 \pm$ 9.7 per $100 \mu \mathrm{m}$ (Fig. 5.1.C).

The palp troughs showed a clear dominance of AMPS in almost every area of the palp (Fig. 5.1).

Ventral margin. The ventral palp margin was characterized by a lack of palp crests, due to their progressive reduction ventrally. Two areas were distinguished on the ventral palp margin based on mucocyte distribution (Fig. 7). The first area corresponded to the anteriormost two-thirds of the ventral margin (Fig. 7.2); the second corresponded to the ventro-posteriormost extremity of the palp (Fig. 7.2),

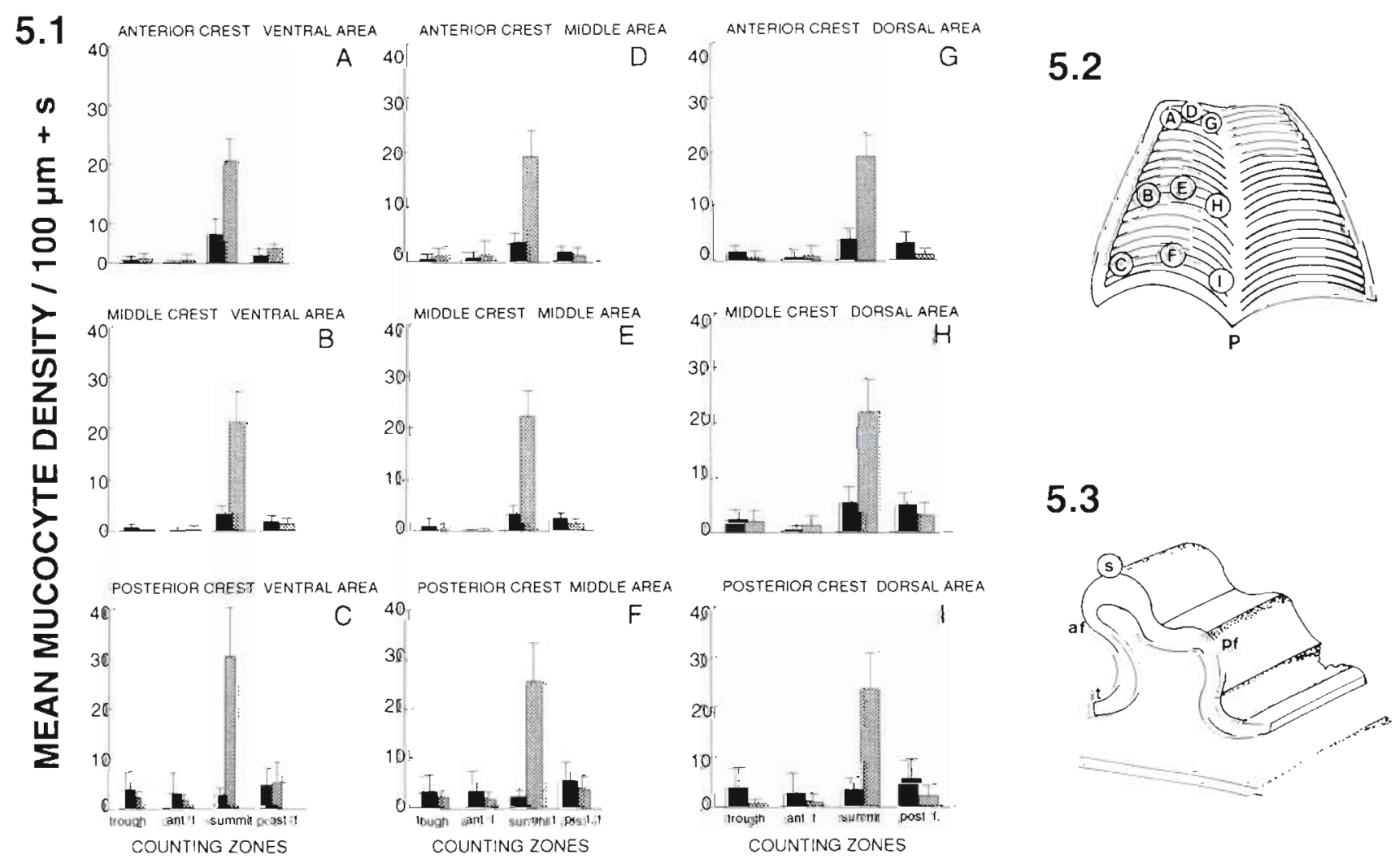

acid secretion

mixed secretion

Fig. 5. Placopecten magellanicus. Mucocyte types and distribution (means + standard deviations) on palp ridged surface, excluding ventral margin and oral groove. (5.1) Mucocyte distribution at 9 areas (A to I) indicated in Fig. 5.2. (5.2) Diagram of labial palp ridged surface, showing counting areas (A to 1). P: posterior region. (5.3) Diagram of a palp crest, showing counting zones. af: anterior fold pf: posterior fold; s: summit; t: trough 


\section{1}

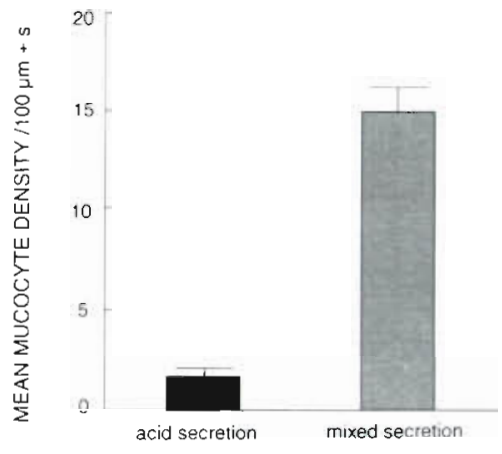

SECRETION TYPE

\section{2}

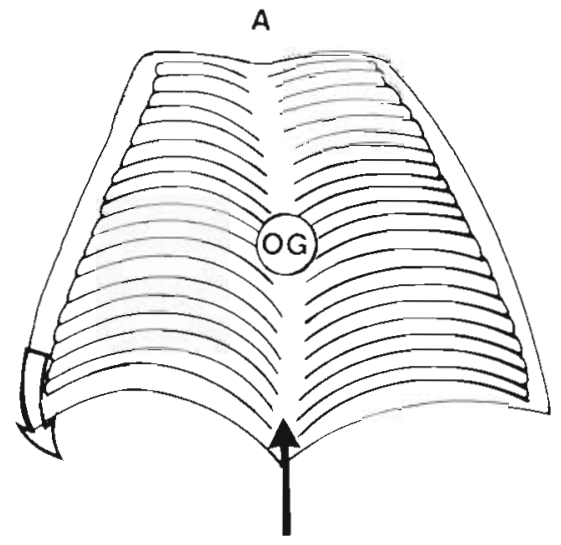

Fig. 6. Placopecten magellanicus. Mucocyte types and distribution (means + standard deviations) in palp oral groove. (6.1) Mucocyte types and density throughout the oral groove. (6.2) Diagram of palp ridged surface, showing position of oral groove (OG). Bold arrow denotes arrival of mucus slurry from gill arch, hollow arrow shows rejection pathway from ventral margin. Dominant pallial current postero-anterior. A: anterior orientation

which in live specimens was curled such that the 2 smooth surfaces were apposed. The majority of the AMPS were situated on the posterior area where they were almost twice as dense as the MMPS (Fig. 7.1). The MMPS largely dominated the anteriormost area: $29.8 \pm 10.7$ per $100 \mu \mathrm{m}$ compared to only $2.9 \pm 4.0$ per $100 \mu \mathrm{m}$ for the AMPS.

In vivo observations. Endoscopic observations could not be performed on the scallop palps due to their extreme sensitivity, constant contraction of the gills, and the physical barrier of the hypertrophied arborescent lips. The mechanisms of particle treatment by the palps could thus only be inferred from observations of the transport of carmine particles on dissected specimens and mucocyte distribution. Arrival of material is via the oral groove situated between the inner and outer palps (Fig. 6) and, in contrast to Mytilus edulis, material arriving at the palps is in the form of a lowviscosity slurry (Beninger et al. 1992). Unless the ingestive capacity of the scallop is overloaded, this material can be transported directly to the mouth. Overloading of the ingestive capacity can induce rejection from the palps; in this case particles were observed to accumulate on the ventro-posterior margin of the palp, as in $M$. edulis (area $C$, Fig 5 and area P, Fig. 7; Fig. 6), from whence they were transferred to the mantle, and no particles were observed in the dorso-posterior region of this organ (areas $G-I$, Fig. 5)

\section{DISCUSSION}

\section{Mytilus edulis}

The present observations of mucocyte distribution and in vivo particle treatment reveal the Mytilus edulis labial palps to be extremely complex organs, whose functioning can nonetheless be easily understood as components of ingestion or rejection. Particles arrive on the densely ciliated surface of the palp dorsal fold (Beninger et al. 1995) from the ventral particle groove of the gill, as has been shown previously in this and other species possessing a dorsal fold and gill ventral groove (Foster-Smith 1975, 1978, Ward et al. 1993). The dorsal fold is shown here to intervene in particle treatment to a greater extent than was previously believed (Foster-Smith 1975, 1978). In effect, by obstructing or revealing the palp particle groove, the behavior of the dorsal fold determines whether the incoming material is destined for ingestion or rejection; only material admitted to the palp particle groove is directed anteriorly for ingestion. Since at this stage the incoming material is in the form of distinct mucus-particle cords, thus precluding any particle selection, this behavior must be considered a means of ingestion volume regulation when the ingestive/handling capacity of the organism is saturated.

The dominance of AMPS and ADMPS on the dorsal fold suggests that the incoming mucus-particle cord is rendered more viscous and stable as it passes over this surface. This may be necessary because the dorsal fold is a much more exposed surface than the gill particle groove, and arriving cords must travel perpendicular to the current flow in this region. It is also necessary for 1 of the 2 possible fates of the cord: rejection, where it is important that the material not disperse over the palp surface and into the pallial cavity, where it would again impinge upon the frontal surface of the gills. The stabilized, rejected cords are thus shunted along the palp crests to the postero-ventral margin of the palp, which is also rich in AMPS, prior to rejection. It should be noted that the entire sequence of rejection appears to rely upon viscous mucopolysaccharides as the transporting medium. 


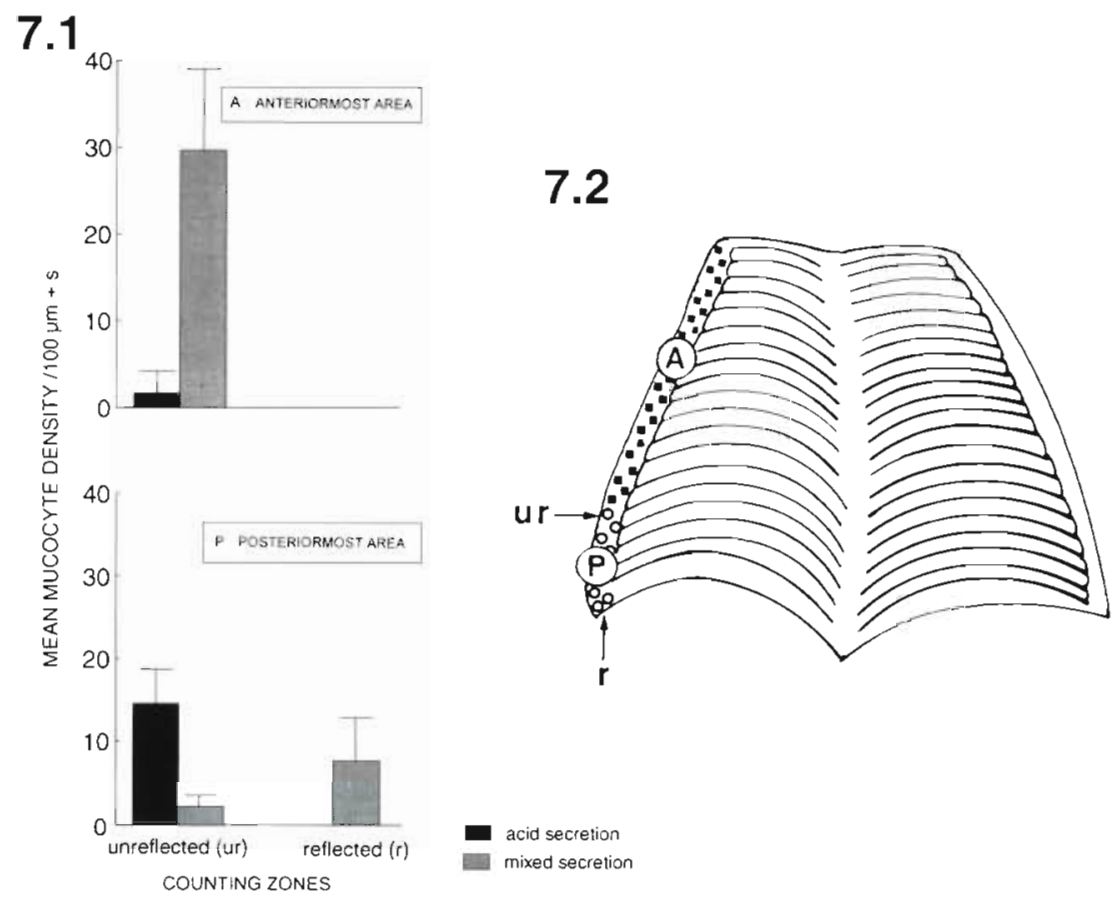

Fig. 7. Placopecten magellanicus. Mucocyte types and distribution (means + standard deviations) on ventral margin. (7.1) Mucocyte distribution in 2 counting areas shown in Fig. 7.2. (7.2) Posteriormost area divided into 2 counting zones: unreflected surface (ur) and reflected surface (r)

\section{Placopecten magellanicus}

The similarity of the rejection pathways in Mytilus edulis observed using either carmine particles on opened specimens or endoscopy suggests that the examination of carmine particle transport on the palps of opened Placopecten magellanicus is valid for the study of rejection processes in this species.

As in Mytilus edulis, the ventral margin of the Placopecten magellanicus palp is the pathway for pseudofeces. The dominance of AMPS in this area would anchor the pseudofeces to the rejecting surface until it arrives at the reflected tip of the palp, where the material could leave the palp surface due to the sole presence of MMPS (Fig. 5.1, 5.2). It should be noted that in the case of the Pectinidae, voidance of pseudofeces is accomplished by valve clapping (Yonge 1967, Morton 1979), hence the transport of pseudofeces into the general infrabranchial chamber of the mantle

The second possible fate for the mucus-particle cords arriving on the palp dorsal fold is preparation for ingestion. As has been pointed out previously, ingestion in bivalves appears to be associated with a relatively low-viscosity mucopolysaccharide transporting medium (Bernard 1974, Beninger et al. 1991, 1992) which is maintained through to the stomach (Beninger et al. 1991, Beninger \& Le Pennec 1993, Ward et al. 1994). A low-viscosity medium is also a prerequisite for particle selection (Beninger et al. 1990, 1992). It is obvious that a stabilized mucusparticle cord is not amenable to either of these contexts, and this has been the source of some puzzlement in the past (Newell \& Jordan 1983, Beninger et al. 1990). Newell \& Jordan (1983) first proposed that the mechanical action of the oyster palp might fluidize the mucus-particle masses and thus allow selection to operate on individual particles; this was later supported by endoscopic observations on Crassostrea virginica (Ward et al. 1994). The results of the present study demonstrate a dual mechanism of cord fluidization in Mytilus edulis: mechanical (the kneading of the palp ridges in the palp oral groove) and biochemical (the addition of NMPS by the crest summits to the cord in the palp particle groove). The fluidized cord is thus suitable for both ingestion and particle selection. cavity may be effected without negative consequences in these species but not in $M$. edulis.

As mentioned in the qualitative observations of Beninger et al. (1990), the mucocyte density on the palp ridged surface is much lower than that of the gills: $<30$ per $100 \mu \mathrm{m}$, compared to up to 60 per $100 \mu \mathrm{m}$ on the gill principal filaments. However, it is clear that mucus is added at the level of the palps, and on the crest summits the dominance of MMPS mucocytes suggests that this surface may function as a detour site to regulate ingestion under conditions of temporary ingestive overload. Foster-Smith $(1975,1978)$ described the formation of acceptance tracts on the crests of labial palps lacking a dorsal fold and palp particle groove, as in P. magellanicus; it is probable that ingestive treatment here follows the pattern observed on the other surfaces studied (see above) in the use of low-viscosity mucus as a transport medium.

\section{Particle selection}

Particles may be rejected as pseudofeces either because the ingestive/handling capacity of the specimen is overloaded (ingestion volume control) or the particles themselves are unsuitable (selection). While rejection for ingestion volume control involves trans- 
port of entire mucus cords to the palp rejection site (ventro-posterior margin), selection must operate on individual particles. The rejection tracts for particles extracted from the fluidized cords are the crest troughs. Although it is not possible to observe the actual entry of particles into these troughs, their exit from the troughs and onto the palp rejection site has been observed both in dissected specimens (Nelson 1960, Ansell 1961) and in vivo (Foster-Smith 1975, 1978, Beninger et al. in press). The high density of AMPS in the crest troughs of both Mytilus edulis and Placopectan magellanicus is thus again related to the transport of material toward an exposed surface, counter to the current flow; this pattern has been consistently observed in particle transport on bivalve pallial surfaces. Conversely, the transport of material on enclosed or semi-enclosed pallial surfaces appears to be associated with relatively low-viscosity MPS and parallel water flow (Beninger et al. 1993, Beninger et al. in press, this study)

One immediate consequence of the difference between the homorhabdic and heterorhabdic gill structure is the division of labour which is possible on the heterorhabdic but not the homorhabdic gill (Beninger et al. 1992, 1993). This specialization allows the scallop gill to regulate ingestion volume using different filament and mucus types (Beninger et al. 1992), and Atkins (1937) reported that particle selection was also effected using principal filaments for material to be ingested and ordinary filaments for material to be rejected. It is thus probable that the palps of Mytilus edulis and Placopecten magellanicus do not perform the same tasks to the same degree. Since in the homorhabdic $M$. edulis all material from the gills is passed anteriorly to the palps, this must be a major site of both ingestion volume control and particle selection, whereas in the heterorhabdic $P$. magellanicus much of these 2 functions may be performed by the gill prior to arrival of material on the palps. The mussel palp may thus be viewed as the major site for ingestion volume control and particle selection, whereas the scallop palp probably plays a secondary role in both of these functions.

Further studies on the labial palps of other bivalve species representing variations of the homorhabdic/ heterorhabdic gill type may reveal whether the greater anatomical complexity which characterizes the Mytilus edulis labial palps is a necessary condition for the greater role these organs play in particle processing, compared to the simpler palps of Placopecten magellanicus. The present study suggests that the nature of particle processing by the labial palps, and by extension the other pallial organs (lips, mantle), is dependent upon the gill type. A much clearer picture of particle processing in bivalves appears to be emerging with the resurgence in interest in the anatomy and physiology of feeding and the introduction and combination of new investigative techniques.

Acknowledgements. The authors thank M. L. Blanchard for his excellent photographic work. We are grateful to Drs E. Ward and B. MacDonald for use of facilities at the University of New Brunswick (Saint John). S.S.J. thanks Dr S. C. Courtenay for comments on preliminary drafts of some sections. This study was funded by research grants from the Natural Sciences and Engineering Research Council (NSERC) and the Faculté d'études supérieures et de la recherche de l'Université de Moncton to P. G. B.

\section{LITERATURE CITED}

Ansell AD (1961) The functional morphology of the British species of Veneracea (Eulamellibranchia). J Mar Biol Ass UK 41:489-515

Atkins D (1937) On the ciliary mechanisms and interrelationships of lamellibranchs. Part II; Sorting devices on the gills. Q J Microsc Sci 79:339-373

Beninger PG, Auffret M, Le Pennec M(1990) The peribuccal organs of Placopecten magellanicus and Chlamys varia (Mollusca: Bivalvia): structure, ultrastructure and implications for feeding. I. The labial palps. Mar Biol 107: 215-223

Beninger PG, Dufour SC, Bourque J (in press) Particle processing mechanisms of the eulamellibranch bivalves Spisula solidissina and Mya arenaria. Mar Ecol Prog Ser

Beninger PG, Le Pennec M (1993) Histochemistry of the bucco-oesophageal glands of Mytilus edulis: the importance of mucus in ingestion. J Mar Biol Ass UK 73: $237-240$

Beninger PG, Le Pennec M, Donval A (1991) Mode of particle ingestion in five species of suspension-feeding bivalve molluscs. Mar Biol 108:255-261

Beninger PG, St-Jean SD, Poussart Y (1995) Labial palps of the blue mussel Mytilus edulis (Bivalvia: Mytilidae). Mar Biol 123:293-303

Beninger PG, St-Jean S, Poussart Y, Ward EJ (1993) Gill function and mucocyte distribution in Placopecten magellanicus and Mytilus edulis (Mollusca: Bivalvia): the role of mucus in particle transport. Mar Ecol Prog Ser 98:275-282

Beninger PG, Ward JE, MacDonald BA, Thompson RJ (1992) Feeding processes of the gill in Placopecten magellanicus (Gmelin) (Mollusca: Bivalvia) as revealed using video endoscopy. Mar Biol 114:281-288

Bernard FR (1974) Particle sorting and labial palp function in the Pacific oyster Crassostrea gigas (Thunberg, 1795). Biol Bull (Woods Hole) 146:1-10

Foster-Smith RL (1975) The role of mucus in the mechanism of feeding in three filter-feeding bivalves. Proc Malacol Soc Lond 41:571-588

Foster-Smith RL (1978) The function of the pallial organs of three bivalves in controlling ingestion. J Mollusc Stud 44 : $83-99$

Kellogg JL (1915) Ciliary mechanisms of lamellibranchs with descriptions of anatomy. J Morphol 26:625-701

Kiørboe T, Mohlenberg F (1981) Particle selection in suspension-feeding bivalves. Mar Ecol Prog Ser 5:291-296

Morton B (1979) A comparison of lip structure and function correlated with other aspects of the functional morphology of Lima lima, Limaria (Platilimaria) fragilis, and Limaria 
(Platilimaria) hongkongensis sp. nov. (Bivalvia: Limacea). Can J Zool 57:728-742

Nelson TC (1960) The feeding mechanism of the oyster. II. On the gills and palps of Ostrea edulis, Crassostrea virginica, and C. angulata. J Morphol 107:163-191 + 2 plates

Newell RIE, Jordan SJ (1983) Preferential ingestion of organic material by the American oyster Crassostrea virginica. Mar Ecol Prog Ser 13:47-53

Shumway SE, Cucci TL, Newell RC, Yentsch CM (1985) Particle selection, ingestion and absorption in filter-feeding bivalves. J Exp Mar Biol Ecol 91:77-92

Tankersley RA, Dimock RV Jr (1992) Quantitative analysis of the structure and function of the marsupial gills of the freshwater mussel Anodonta cataracta. Biol Bull (Woods Hole) 182:145-154

Tankersley RA, Dimock RV Jr (1993) Endoscopic visualization of the functional morphology of the unionid mussel Pyganodon cataracta. Can J Zool 71:811-819

This article was presented by J.M. Lawrence (Senior Editorial Advisor), Tampa, Florida, USA
Theisen BF (1982) Variation in size of gills, labial palps, and adductor muscle in Mytilus edulis L. (Bivalvia) from Danish waters. Ophelia 21(1): 49-63

Ward JE, Beninger PG, MacDonald BA, Thompson RJ (1991) Direct observations of feeding structure and mechanisms in bivalve mollusks using endoscopic examination and video image analysis. Mar Biol 111:287-291

Ward JE, MacDonald BA, Thompson RJ, Beninger PG (1993) Mechanisms of suspension-feeding in bivalves: resolution of current controversies by means of endoscopy. Limnol Oceanogr 38:265-272

Ward JE, Newell RIE, Thompson RJ, MacDonald BA (1994) In vivo studies of suspension-feeding processes in the eastern oyster, Crassostrea virginica (Gmelin). Biol Bull (Woods Hole) 186:221-240

Yonge CM (1967) Observations on Pedum spondyloideum (Chemnitz) Gmelin, a scallop associated with reef-building corals. Proc Malacol Soc Lond 37:311-323

Manuscript first received: September 2, 1996

Revised version accepted: December 17, 1996 